\title{
ESTUDIO DE LOS FACTORES LIMITANTES PARA LA OBTENCIÓN DE PLANTAS HAPLOIDES DE Coffea arabica
}

\author{
Ligia Belén Suescún Peñaranda*, Juan Carlos Herrera Pinilla (ID **, José Ricardo Acuña Zornosa (ID) ***
}

\begin{abstract}
Suescún, L. B., Herrera, J. C., \& Acuña-Zornosa, J. R. (2020). Estudio de los factores limitantes para la obtención de plantas haploides de Coffea arabica. Revista Cenicafé, 71(1), 32-47. https://doi.org/10.38141/10778/1118
\end{abstract}

El desarrollo de un método eficiente para obtener plantas haploides de café requiere del estudio de los factores más limitantes. En este trabajo se evaluó el desarrollo de los gametos masculinos en relación con el estado fenológico de la flor de $C$. arabica, se evaluaron tratamientos de desinfección de las flores, tratamientos para el aislamiento y purificación de las microsporas, se estudió el efecto térmico sobre la inducción de la androgénesis y, por último, se evaluaron tratamientos con agentes antimitóticos para la duplicación cromosómica de tejidos haploides. Para inducir el proceso de androgénesis, se determinó que los botones florales entre 1,0 y 1,7 cm de longitud contenían el mayor porcentaje de células gaméticas en los estados uninucleado tardío y binucleado temprano, cruciales para el cambio ontogénico. Se determinó que el menor porcentaje de contaminación microbiana y oxidación biológica se logró con el uso de hipoclorito de calcio combinado con antioxidantes. El aislamiento y purificación de las microsporas se obtuvo mediante maceración mecánica de las anteras y filtración de las células gaméticas en mallas de 40 y 70 micras junto con el empleo de Percoll en gradientes superiores al 50\%. La mayor inducción androgénica de las microsporas se consiguió incubando los botones florales desprendidos de la rama a $4{ }^{\circ} \mathrm{C}$, observándose divisiones celulares y formación de colonias multicelulares. La aplicación de Colchicina (1\%) a meristemos de plantas haploides de $C$. arabica permitió la obtención de ramas con hojas que duplicaron su material cromosómico y cambiaron su morfología.

Palabras clave: Androgénesis, cultivo microsporas, haploides, Coffea arabica.

\section{STUDY OF THE LIMITING FACTORS FOR OBTAINING HAPLOID PLANTS FROM Coffea arabica}

The development of an efficient method to obtain coffee haploid plants requires the study of the most limiting factors. This work of research evaluated the development of male gametes in relation to the phenological state of the $C$. arabica flower, flower disinfection treatments, treatments for isolation and purification of microspores. The thermal effect on the induction of androgenesis and the treatments with antimitotic agents for chromosomal duplication of haploid tissues were also evaluated. To induce the androgenesis process, flower buds between 1 and $1.7 \mathrm{~cm}$ in length were determined to contain the highest percentage of gametic cells in the late uninucleate and early binucleate states, crucial for ontogenetic change. It was established that the lowest percentage of microbial contamination and biological oxidation was achieved with the use of calcium hypochlorite combined with antioxidants. The isolation and purification of the microspores was obtained by mechanical maceration of the anthers and filtration of the gametic cells in 40 and 70 micron-meshes together with the use of Percoll in gradients higher than $50 \%$. The greatest androgenic induction of microspores was achieved by incubating the flower buds detached from the branch at $4^{\circ} \mathrm{C}$, observing cell divisions and multicellular colonies formation. The application of Colchicine $(1 \%)$ to meristems of haploid plants of C. arabica allowed to obtain branches with leaves that duplicated their chromosomal material and changed their morphology.

Keywords: Androgenesis, microspore culture, haploids, Coffea arabica

\footnotetext{
* Ingeniera de Producción Biotecnología, M.Sc. Biología Aplicada.

** Biólogo, M.Sc. Mejoramiento Genético de Plantas, Ph.D. Genómica y Mejoramiento Genético de Plantas. Nestlé, Francia. https://orcid.org/0000-0002-4855-6732.

*** Investigador Científico III. Disciplina de Fisiología Vegetal, Centro Nacional de Investigaciones de Café, Cenicafé. Chinchiná, Caldas, Colombia. https://orcid.org/0000-0001-6935-2264.
} 
La androgénesis es un proceso natural que conlleva la formación y desarrollo de individuos haploides a partir de células gaméticas, el cual ocurre a frecuencias muy bajas. Los organismos haploides se caracterizan por tener la mitad del número de cromosomas de su especie, lo que les confiere características fenotípicas singulares, que los hacen muy interesantes para el desarrollo de investigaciones genéticas. En el mejoramiento genético vegetal su principal utilidad es la obtención rápida de plantas doble-haploides, a través de la duplicación de su contenido genético para obtener líneas completamente homocigóticas (Kasha, 2005). Existen diferentes métodos para la obtención de haploides en el laboratorio, los cuales se denominan "haplométodos". Dentro de los más conocidos están: el cultivo in vitro de anteras y el cultivo de microsporas. En estos, las células gaméticas masculinas o microsporas son inducidas a cambiar su curso ontogénico normal, que las debería conducir a formar el grano de polen, por una vía que se denomina "androgénesis", y que conduce al desarrollo de un tejido esporofítico haploide. Este proceso es dependiente de muchos factores tales como el genotipo, el estado fisiológico del material parental, el estado de desarrollo del polen, la composición del medio de cultivo y el tipo de estrés inductivo.

Aunque las bases biológicas que gobiernan la androgénesis no han sido totalmente entendidas, existen trabajos concluyentes sobre los efectos favorables del estrés inductivo en el cultivo de microsporas que provocan la formación de células embriogénicas. Estos tratamientos incluyen la utilización de choques térmicos con bajas o altas temperaturas, medios de cultivo con déficit de carbohidratos o la aplicación de sustancias inhibidoras de la división celular (Kasha, 2005; Zoriniants,
Tashpulatov, Heberle-Bors y Touraev, 2005; Carpeta et al., 2006). Una vez regenerado el material haploide es fundamental lograr la producción de plantas doble-haploides homocigotas que podrían utilizarse como padres en cruzamientos intra- o inter-específicos, así como, en la producción de líneas puras con potencial comercial. El principal mecanismo de duplicación cromosómica del tejido haploide es la exposición a agentes antimitóticos (por ejemplo, colchicina, trifluralina). El éxito de la duplicación cromosómica requiere de un balance exacto entre concentración y tiempo de exposición al antimitótico para cada genotipo particular. En el caso del café, existen algunos intentos para desarrollar haplométodos, aunque con pocos resultados exitosos (Sharp et al., 1973; Neuenschwander et al., 1993; Raghuramulu y Prakash, 1996). En el año 2002, en Cenicafé se logró por primera vez la inducción y regeneración de plantas haploides a partir de microsporas aisladas de la especie Coffea arabica (Herrera et al., 2002). Como resultado de este trabajo, se desarrolló un protocolo de base y se obtuvieron varios individuos haploides, los cuales se encuentran actualmente sembrados en el campo y han servido de base para diferentes estudios. A pesar de estos avances, el uso de los haploides continúa siendo limitado por la baja eficiencia de regeneración. $\mathrm{Su}$ implementación como una herramienta para el mejoramiento del café requiere un trabajo de optimización del proceso, a fin de superar limitaciones relacionadas con el estado apropiado de los gametos masculinos en relación con el desarrollo de la flor del café, los protocolos de desinfección de las flores, el aislamiento y purificación de las microsporas, el tratamiento térmico que estimule la inducción androgénica en las microsporas y la duplicación cromosómica de los tejidos haploides. 


\section{MATERIALES Y MÉTODOS}

\section{Estado de los gametos masculinos y su} relación con el desarrollo de la flor del café.

Se recolectaron botones florales de plantas de C. arabica (Híbridos F1 de Variedad Castillo ${ }^{\circledR}$ x Variedades S795, S288 y BA2 de C. arabica) entre 0,5 y $1,9 \mathrm{~cm}$ de longitud, los cuales se agruparon en siete categorías con intervalos de 0,2 cm entre cada una. Para cada categoría se disecaron las anteras, se midieron y se fijaron en solución de Carnoy. Se aislaron las células gaméticas y, mediante observación al microscopio óptico, se clasificaron de la siguiente forma: (i) células madre del polen; (ii) tétradas; (iii) microsporas uninucleadas tempranas; (iv) microsporas uninucleadas tardías; (v) microsporas binucleadas tempranas; (vi) microsporas uninucleadas tardías; (vii) granos de polen maduro. El estado óptimo para el cultivo de microsporas es cuando las células gaméticas se encuentran en estado uninucleado tardío o binucleado temprano (Herrera et al., 2002).

\section{Desinfección de los botones florales.} Se evaluaron cinco tratamientos para la desinfección de botones florales de C. arabica, empleados en otras especies vegetales para el cultivo in vitro de anteras (Tabla 1). Los botones fueron recolectados en el campo, en horas de la mañana y transportados al laboratorio en frascos de vidrio, con servilletas humedecidas. Luego, se aplicaron los tratamientos de desinfección y después de una semana de cultivo se evaluó el porcentaje de contaminación microbiana y de oxidación del tejido de las anteras por cada tratamiento.

Aislamiento de microsporas. Después de recolectar botones florales en el estado de desarrollo apropiado para la inducción androgénica, se desinfectaron y extrajeron las anteras. Para el aislamiento de las microsporas se aplicaron tres tratamientos con cuatro repeticiones, 100 anteras por cada tratamiento y como variable de respuesta se registró el número de microsporas por mililitro (Tabla 2).

Purificación de las microsporas. Para la purificación de las microsporas se utilizaron tres gradientes de Percoll $^{\circledR}(50 \%, 60 \%$ y $70 \%(\mathrm{v} / \mathrm{v}))$, diluido en medio de cultivo "MA", compuesto por las sales de Murashige \& Skoog $(0,5 \mathrm{X})$, $64 \mathrm{mg} \mathrm{L}^{-1}$ de manitol y $0,6 \mathrm{~g} \mathrm{~L}^{-1}$ de cisteína. Las microsporas se transfirieron a un tubo de vidrio de $15 \mathrm{~mL}$ sobre $4 \mathrm{~mL}$ del tratamiento de Percoll ${ }^{\circledR}$. La suspensión se centrifugó a 700 rpm, durante $6 \mathrm{~min}$, a $10^{\circ} \mathrm{C}$, las microsporas viables, que se distribuyeron en la interfase de la solución, se aspiraron lentamente con una micropipeta y se transfirieron a otro tubo estéril. Las microsporas se lavaron dos veces con $2 \mathrm{~mL}$ de medio MA, centrifugando a 700 rpm, durante 1 min para retirar el sobrenadante y se resuspendieron en $1 \mathrm{~mL}$ de medio "MC" compuesto por sales minerales B5 de Gamborg (1X), agua de coco $\left(160 \mathrm{~mL} \mathrm{~L}^{-1}\right)$, glutamina (250 $\left.\mathrm{mg} \mathrm{L}^{-1}\right)$, glicina $\left(2 \mathrm{mg} \mathrm{L}^{-1}\right)$, cisteína (150 $\mathrm{mg} \mathrm{L}^{-1}$ ), inositol (100 $\left.\mathrm{mg} \mathrm{L}^{-1}\right)$, MES (600 mg $\left.\mathrm{L}^{-1}\right)$, PVP-10 (200 mg L-1), maltosa (200 mg $\left.\mathrm{L}^{-1}\right)$, ácido naftalén acético $\left(0,3 \mathrm{mg} \mathrm{L}^{-1}\right) \mathrm{y}$ quinetina $\left(0,1 \mathrm{mg} \mathrm{L}^{-1}\right)$, el $\mathrm{pH}$ de la solución se ajustó a 5,8. Finalmente, se registró el número de microsporas $/ \mathrm{mL}$.

Evaluación del efecto del estrés térmico en microsporas de café. Para la inducción de androgénesis se utilizaron tratamientos basados en las investigaciones de Zur et al., (2014) y Rodríguez et al., (2012), aplicando una temperatura de $4^{\circ} \mathrm{C}$ a flores de $C$. arabica desprendidas y no desprendidas de la rama. En el tratamiento con botones florales no desprendidos de la rama se utilizaron ramas de 40-50 cm de longitud que tenían flores con las características morfológicas óptimas para la androgénesis. Después de cortadas las ramas, 
Tabla 1. Descripción de los tratamientos para la desinfección superficial de botones florales de Coffea arabica.

\begin{tabular}{|c|c|c|c|c|}
\hline Tratamiento PI & Tratamiento PII & Tratamiento PIII & Tratamiento PIV & Tratamiento PIV \\
\hline $\begin{array}{l}\text { Lavado en } \\
\text { detergente no } \\
\text { iónico }\end{array}$ & $\begin{array}{l}\text { Lavado en jabón } \\
\text { antimicrobial }\end{array}$ & $\begin{array}{l}\text { Lavado en jabón } \\
\text { antimicrobial }\end{array}$ & $\begin{array}{l}\text { Lavado en jabón } \\
\text { antimicrobial }\end{array}$ & $\begin{array}{l}\text { Lavado en jabón } \\
\text { antimicrobial }\end{array}$ \\
\hline
\end{tabular}

Inmersión en etanol $70 \%, 1 \mathrm{~min}$.

Inmersión en hipoclorito de sodio $50 \%(\mathrm{v} / \mathrm{v})+2$ gotas de Tween $20^{\circledR}, 10$ $\min$.

Lavado en solución SL: manitol $(64 \mathrm{~g}$ $\left.\mathrm{L}^{-1}\right)$, cisteína (2 $\mathrm{g} \mathrm{L}^{-1}$ )

Inmersión en
Derosal $~^{\circledR} 500 \mathrm{SC}$
$2 \%(\mathrm{v} / \mathrm{v})+$ cisteína

Siembra medio de MP: sales Murashige y Skoog (1X), cisteína 0,6 $\mathrm{g} \mathrm{L}^{-1}$, sacarosa 30 $\mathrm{g} \mathrm{L}^{-1}$, manitol $30 \mathrm{~g}$ $\mathrm{L}^{-1}$, Phytagel 2,5 g $\mathrm{L}^{-1}, \mathrm{pH} 5,8$.
Inmersión en Timsen ${ }^{\circledR} 20 \%(\mathrm{v} / \mathrm{v})$, $10 \mathrm{~min}$.

Lavado en solución SL: manitol (64 g $\left.\mathrm{L}^{-1}\right)$, cisteína $(2$ $\mathrm{g} \mathrm{L}^{-1}$ )

Inmersión en solución antimicrobial $\mathrm{PPM}^{\mathrm{TM}} 0,5 \%$

\begin{abstract}
Inmersión en hipoclorito de calcio $5 \%(\mathrm{p} / \mathrm{v})+2$ gotas de Tween $20^{\circledR}$
\end{abstract}

Inmersión en $\operatorname{Derosal}^{\circledR} 2 \%(\mathrm{v} / \mathrm{v})$ $5 \mathrm{~min}$.

Inmersión en Inmersión en

$10 \mathrm{~min}$. $10 \mathrm{~min}$.
Inmersión en hipoclorito de calcio 5\% (p/v)
Inmersión en Derosal $^{\circledR} 2 \%(\mathrm{v} / \mathrm{v})$
Lavado en solución A: manitol $(64 \mathrm{~g}$ $\left.\mathrm{L}^{-1}\right)$, metabisulfito de sodio $\left(2 \mathrm{~g} \mathrm{~L}^{-1}\right)$, $\mathrm{PPM}^{\mathrm{TM}}(5 \mathrm{~mL})$.
Desinfección en hipoclorito de calcio $5 \%+2$ gotas de Tween $20^{\circledR}$
Lavado en solución SL + solución antimicrobial РTC ${ }^{\text {TM }} 0,5 \%$

\section{Inmersión en solución antimicrobial PРM $^{\mathrm{TM}} 0,5 \%, 1-2$ min.}

Solución A: manitol (64 g $\left.\mathrm{L}^{-1}\right)$, metabisulfito de sodio (2 $\mathrm{g}$ $\left.\mathrm{L}^{-1}\right), \mathrm{PPM}(5$ $\mathrm{mL})+$ solución antimicrobial PTC ${ }^{\text {TM }} 0,5 \%$

Siembra medio de MP: sales Murashige y Skoog (1X), metabisulfito de sodio $2 \mathrm{mg} \mathrm{L}^{-1}$, sacarosa $30 \mathrm{~g} \mathrm{~L}^{-1}$, manitol $30 \mathrm{~g} \mathrm{~L}^{-1}$, Phytagel 2,5 $\mathrm{g} \mathrm{L}^{-1}$, $\mathrm{pH} 5,8$.

Murashige y Skoog (1X), metabisulfito de sodio $2 \mathrm{mg} \mathrm{L}^{-1}$, sacarosa $30 \mathrm{~g} \mathrm{~L}^{-1}$, manitol $30 \mathrm{~g} \mathrm{~L}^{-1}$, Phytagel 2,5 $\mathrm{g} \mathrm{L}^{-1}$, pH 5,8.$$
\text { MP: sales }
$$

(1X), metabisulfito de sodio $2 \mathrm{mg} \mathrm{L}^{-1}$, sacarosa $30 \mathrm{~g} \mathrm{~L}^{-1}$, manitol $30 \mathrm{~g} \mathrm{~L}^{-1}$, Phytagel 2,5 $\mathrm{g} \mathrm{L}^{-1}$, $\mathrm{pH} 5,8$. $\mathrm{pH} \mathrm{5,8}$ 
Tabla 2. Descripción de los tratamientos para el aislamiento de microsporas a partir de anteras seleccionadas para el proceso de androgénesis en Coffea arabica.

\begin{tabular}{|c|c|c|}
\hline Tratamiento AI & Tratamiento AII & Tratamiento AIII \\
\hline 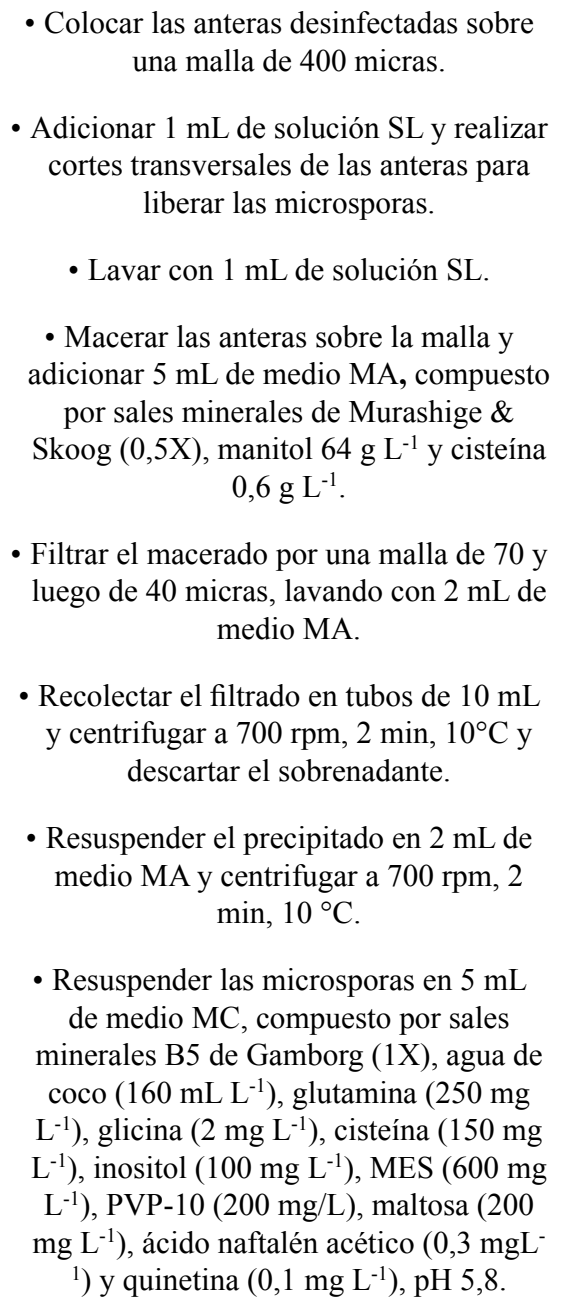 & $\begin{array}{c}\text { - Colocar las anteras } \\
\text { desinfectadas en } \\
\text { recipiente de vidrio y } \\
\text { hacer cortes transversales } \\
\text { para liberar microsporas. } \\
\text { - Adicionar } 5 \mathrm{~mL} \text { de medio } \\
\text { MA ( } 1 \mathrm{~mL} / 5 \text { anteras). } \\
\text { - Cubrir con papel } \\
\text { aluminio el frasco y } \\
\text { agitar (110 rpm), } 10^{\circ} \mathrm{C}, \\
\text { durante } 24-48 \text { horas, en } \\
\text { oscuridad. } \\
\text { - Filtrar la solución por } \\
\text { una malla de } 40 \text { micras } \\
\text { y recolectar el filtrado } \\
\text { en tubos de } 10 \mathrm{~mL}, \\
\text { centrifugar } 700 \text { rpm } 2 \\
\text { min, } 10^{\circ} \mathrm{C}, \text { descartar el } \\
\text { sobrenadante. } \\
\text { • Resuspender las } \\
\text { microsporas en } 2 \mathrm{~mL} \text { de } \\
\text { medio MA y centrifugar } \\
\text { a } 700 \text { rpm, } 2 \text { min, } 10^{\circ} \mathrm{C}, \\
\text { descartar el sobrenadante } \\
\text { y repetir este proceso una } \\
\text { vez más. }\end{array}$ & $\begin{array}{c}\text { • Sembrar anteras } \\
\text { desinfectadas en medio MA } \\
\text { solidificado con Agarosa } \\
1 \% \text {, durante una semana. } \\
\text { - Recolectar las anteras y } \\
\text { macerarlas para liberar las } \\
\text { microsporas, adicionar } 5 \mathrm{~mL} \\
\text { de medio MA. } \\
\text { - Filtrar las anteras por una } \\
\text { malla de } 40 \text { micras. } \\
\text { - Centrifugar a } 700 \mathrm{rpm} \\
\text { durante } 2 \text { min y descartar el } \\
\text { sobrenadante. } \\
\text { - Recolectar el filtrado } \\
\text { en tubos de } 10 \mathrm{~mL} \mathrm{y} \\
\text { centrifugar } 700 \mathrm{rpm}, 2 \\
\text { min, } 10^{\circ} \mathrm{C}, \text { descartar el } \\
\text { sobrenadante. } \\
\text { • Resuspender las } \\
\text { microsporas en } 2 \mathrm{~mL} \mathrm{de} \\
\text { medio MA, centrifugar } \\
\text { a } 700 \text { rpm, } 2 \text { min, } 0^{\circ} \mathrm{C}, \\
\text { descartar el sobrenadante y } \\
\text { repetir este proceso una vez } \\
\text { más. } \\
\text { • Resuspender las } \\
\text { microsporas en } 5 \mathrm{~mL} \mathrm{de} \\
\text { medio } \mathrm{MC} .\end{array}$ \\
\hline
\end{tabular}

en la herida donde se realizó el corte se colocó una mota de algodón humedecida con agua destilada. Las ramas fueron colocadas en bolsas de papel aluminio a $4^{\circ} \mathrm{C}$, en condiciones de oscuridad, durante 7 días. En el tratamiento con los botones florales con desprendimiento de la rama, estos fueron recolectados en frascos de vidrio, e incubados a $4^{\circ} \mathrm{C}$ en condiciones de oscuridad, durante cinco días. Se utilizó un tratamiento control donde los botones florales, desprendidos y en la rama, fueron conservados a temperatura ambiente. Después de aplicar los tratamientos, las microsporas se aislaron, purificaron y diluyeron a una densidad de $1 \times 10^{5}$ microsporas $/ \mathrm{mL}$. Después, estas se incubaron en cajas de Petri $(5,4 \times 1,5 \mathrm{~cm})$ 
en oscuridad, a $4^{\circ} \mathrm{C}$ durante tres días. Luego, las microsporas fueron transferidas a tubos de $15 \mathrm{~mL}$, se lavaron dos veces mediante centrifugación (700 rpm, $1 \mathrm{~min}$ ) con $2 \mathrm{~mL}$ de medio "MA" y las microsporas decantadas se colocaron en $2 \mathrm{~mL}$ de medio de cultivo MC. Sobre un portaobjetos se depositó una alícuota y se le adicionaron $8 \mu \mathrm{L}$ de diacetato de fluoresceína $\left(5 \mathrm{mg} \mathrm{mL}^{-1}\right)$, para verificar el porcentaje de células vivas mediante observación con microscopio de fluorescencia. Finalmente, las microsporas se incubaron a $27^{\circ} \mathrm{C}$ en la oscuridad, en placas multipozos con medio "MC" solidificado con agarosa (1\%) y después de tres semanas se registró el porcentaje de microsporas en estado de división, con la ayuda de un microscopio motorizado Nikon 90i (objetivo 40X), por cada placa se registraron cinco campos.

\section{Duplicación cromosómica in vivo de plantas} haploides de $\boldsymbol{C}$. arabica. La metodología propuesta por Berthou (1975) y Noirot (1978) fue seleccionada para la duplicación de cromosomas y consistió en inducir el crecimiento de nuevos brotes caulinares mediante el tratamiento in vivo de meristemas apicales con agentes antimitóticos. Se utilizaron plantas haploides de C. arabica var. Colombia de 15 años de edad, previamente obtenidas por Herrera et al. (2002), y que estaban sembradas en el campo en la Estación Experimental de Naranjal, Chinchiná (Caldas). Se evaluó el efecto antimitótico de la Colchicina 1\% (TRA1) y la Trifluralina $0,1 \%$ (TRA2) sobre yemas apicales de la planta. En cada yema se realizó un corte a nivel del entrenudo subterminal o terminal, dejando el meristemo al descubierto y teniendo cuidado de no generar algún daño a la estípula. Luego, se colocó una mota de algodón sobre el área expuesta que estaba impregnada con una solución del antimitótico disuelto en agua de coco $49 \%$ (v/v) y glicerol $49 \%$ (v/v). El tejido se cubrió con una película plastificada "vinipel" por 72 horas. Una vez aparecieron nuevos brotes caulinares con hojas (chupones), se evaluaron con el fin de identificar cambios morfo-anatómicos y cromosómicos en las hojas de estos chupones en comparación con las hojas del resto de la planta haploide. Se realizó una clasificación cualitativa agrupando las ramas con hojas de mayor tamaño, que es una característica de duplicación de cromosomas $(\mathrm{RHD}=$ Ramas Hojas Duplicadas) y ramas con hojas iguales a las del resto de la planta haploide (RHSD= Ramas Hojas Sin Duplicar) (Herrera y Camayo, 2008). Para evaluar los cambios morfológicos y cromosómicos se tomaron cuatro hojas por estado (RHD y RHSD) y para cada uno de los tratamientos (TRA1 y TRA2). Con estas hojas se evaluó la relación longitud/ancho de la hoja ("RELAH"), la densidad estomática (DE), la longitud de las células guardas (LONGE) y el número de cromosomas. La densidad estomática se determinó con el número de estomas por milímetro cuadrado (estomas $/ \mathrm{mm}^{2}$ ), para lo cual se analizaron cuatro láminas con epidermis del envés de las hojas (una para cada hoja). En cada lámina se observaron cuatro campos aleatorios bajo microscopio Nikon 90i, empleando el objetivo 40X, y en cada campo se contó el número de estomas y la longitud de las células guarda de los estomas para la variable LONGE. Para el conteo de cromosomas se recolectó tejido foliar joven en horas de la mañana (8:00 a 11:00 am) y se colocó en una solución de $\alpha$-hydroxiquinolina $(0,05 \%)$, por tres horas, para sincronizar los estados de división celular, posteriormente las hojas se lavaron y se fijaron en solución Carnoy hasta la preparación de los extendidos cromosómicos. El tejido se lavó y tiñó con aceto-carmín, seguidamente se realizó el extendido de una porción del tejido sobre una lámina porta-objetos. Se analizaron tres placas por muestra y en cada placa se observaron cinco metafases y se registró el número de cromosomas. Para cada tratamiento (TRA1 y TRA2) se realizó el análisis de estadística 
descriptiva, de los estados (RHD y RHSD) y de las variables RELAH, DE y LONGE, y análisis de varianza con prueba de comparación de grupos y las diferencias entre los grupos para cada una de las variables medidas se determinaron mediante la prueba de $t$ al $5 \%$.

\section{RESULTADOS Y DISCUSIÓN}

\section{Relación del estado floral y el desarrollo} del polen. En el análisis citológico se observó un desarrollo normal del proceso de microsporogénesis en las anteras de Coffea arabica, evidenciando un desarrollo gametofítico propio de las angiospermas, las células madres inician su diferenciación hasta formar los cuatro núcleos haploides, donde ocurre la división citoplasmática, que conlleva a la formación de la tétrada (Figura 1 a-d). La pared callosa de esta última se rompe y se liberan las microsporas uninucleadas jóvenes o tempranas, las cuales forman una doble pared compuesta por intina y exina, el núcleo se encuentra en el centro de la célula
(Figura 1-e). A continuación, la vacuola se va agrandando, desplazando el núcleo a un costado de la microspora, lo cual diferencia el estado uninucleado tardío (Figura 1-f). En este momento ocurre una división mitótica dando paso al estado binucleado con dos núcleos, uno vegetativo y otro regenerativo, siendo este último un poco más pequeño. Inicialmente la microspora se observa con los dos núcleos juntos, a un costado de la célula (Figura 1-g), pero a medida que se van formando vacuolas y se va llenando el citoplasma de gránulos de almidón, los núcleos se van separando, ubicándose en los polos opuestos de la microspora (Figura 1-h). Finalmente, el núcleo vegetativo se observa grande y denso, ubicándose generalmente en el centro de la célula, en cuanto al núcleo regenerativo se hace más pequeño y difuso, ubicado a un costado de la célula, dando paso a la madurez del grano de polen (Figura 1-i).

Los botones florales se agruparon en siete categorías, con intervalos de $0,2 \mathrm{~cm}$

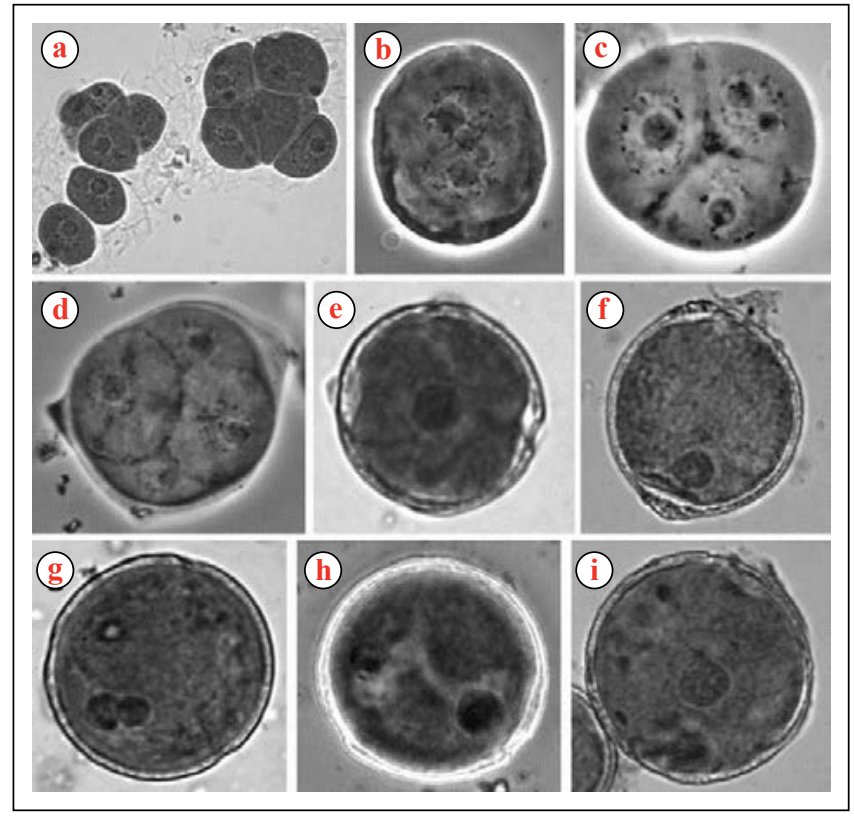

Figura 1. Desarrollo del polen de los híbridos de Coffea arabica. Se detallan los estados más característicos, desde la diferenciación celular (célula madre de polen) hasta la formación de grano de polen maduro. a. Células madres de polen; b. y c. Células en división meiótica, formación de los cuatro núcleos; d. Tétrada; e. Microspora uninucleada temprana o joven; f. Microspora uninucleada tardía; g. Microspora binucleada temprana; $\mathbf{h}$. Microspora binucleada tardía; i. Polen maduro. 
entre cada categoría (Tabla 3), iniciando con botones de $0,5 \mathrm{~cm}$ hasta botones de 1,9 $\mathrm{cm}$ de longitud (Figura 2). En las categorías 1,2 y 3 predominaron las microsporas en estados de desarrollo inmaduros, donde se observaron células madre y algunas tétradas, producto de la división meiótica. El estado uninucleado temprano, se observó en casi todas las categorías, pero con mayor presencia en la categoría 3, mientras que los estados uninucleado tardío y binucleado temprano, cruciales para que se dé el cambio ontogénico en el cultivo in vitro de microsporas, se encontró entre las categorías 4 y 7 , con mayor frecuencia de uninucleado tardío en la categoría 5 y de binucleado temprano en la categoría 7 . Los estados de binucleado tardío y grano de polen maduro se concentraron después de la categoría 6 . Los botones florales entre 1,5 y $1,8 \mathrm{~cm}$ de longitud y de coloración verde crema son apropiados para la inducción del proceso de androgénesis.

Desinfección de botones florales. Con los tratamientos PII y PIII se obtuvieron porcentajes de contaminación microbiana

Tabla 3. Categorización de los botones florales de C. arabica de acuerdo su longitud y el tamaño de sus anteras.

\begin{tabular}{|c|c|c|}
\hline Categoría & Rango de longitud del botón floral $(\mathrm{cm})$ & Longitud promedio de las anteras $(\mathrm{cm})$ \\
\hline 1 & $0,50-0,70$ & 0,41 \\
\hline 2 & $0,71-0,90$ & 0,52 \\
\hline 3 & $0,91-1,10$ & 0,70 \\
\hline 4 & $1,11-1,30$ & 0,74 \\
\hline 5 & $1,31-1,50$ & 0,89 \\
\hline 6 & $1,51-1,70$ & 0,99 \\
\hline 7 & $1,71-1,90$ & 1,04 \\
\hline
\end{tabular}

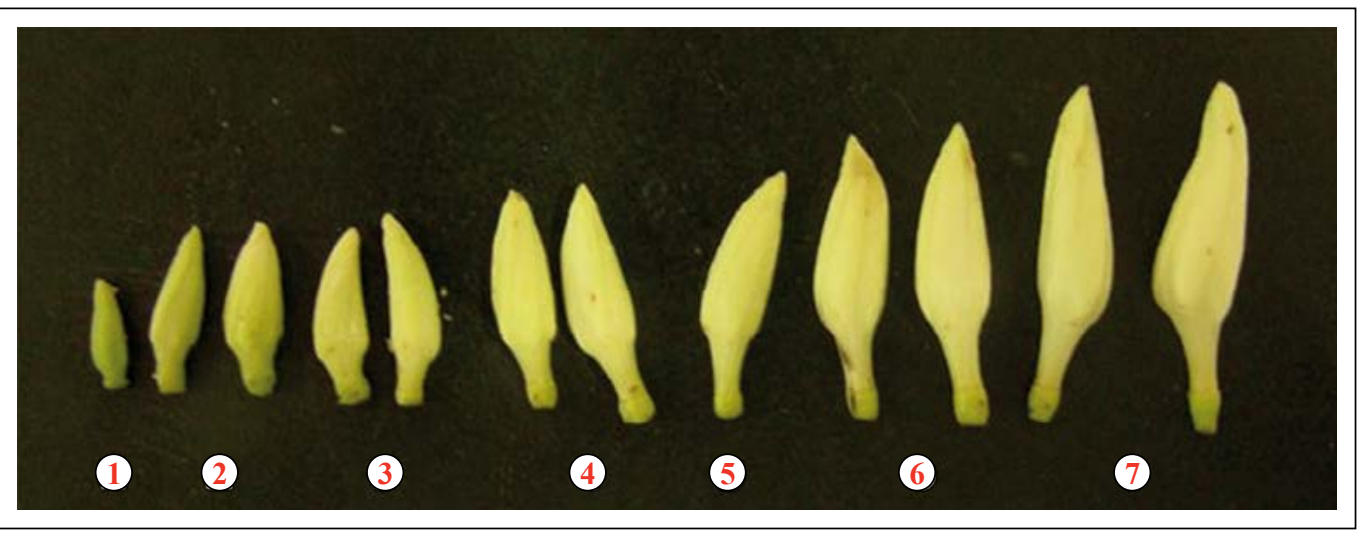

Figura 2. Desarrollo morfológico de los botones florales de C. arabica. Botones florales recolectados de plantas de C. arabica y agrupados en siete categorías de tamaño, de acuerdo la longitud del botón floral y de las anteras. 
bajos $(<30 \%)$, pero el tejido de las anteras se deterioró debido principalmente a procesos de oxidación biológica $(>40 \%)$. En el caso particular del café, los tejidos de la planta son muy vulnerables a la oxidación biológica por efecto abrasivo de los agentes desinfectantes y los cortes que sufren. El hipoclorito de sodio, ampliamente usado como desinfectante en el cultivo in vitro de tejidos y órganos vegetales, produce daños irreversibles en algunos tejidos, razón por la cual se utiliza como alternativa el hipoclorito de calcio. De igual forma, el uso de compuestos antioxidantes como la cisteína y el meta bisulfito de sodio han sido muy efectivos para el control de la oxidación biológica de tejidos u órganos de C. arabica in vitro. Con las modificaciones hechas en los tratamientos PII' y PIII', donde se incluyó como desinfectante hipoclorito de calcio y el uso de meta bisulfito de sodio como antioxidante, se lograron los niveles de contaminación y de oxidación bajos, seleccionando el tratamiento PII' para la desinfección de botones florales (Tabla 1; Figura 3).

Aislamiento de microsporas. Con el tratamiento de aislamiento AI se obtuvo la mayor densidad de microsporas, pero este procedimiento dejó residuos celulares en la suspensión de microsporas por lo que se procedió a evaluar tratamientos de purificación que permitieran obtener suspensiones con microsporas de tamaño uniforme y libre de residuos provenientes del tejido de la antera (Tabla 2, Figura 4).

Purificación de las microsporas. El Percoll ${ }^{\circledR}$ utilizado para la purificación de células, orgánulos y/o virus mediante centrifugación en gradientes de densidad, es adecuado debido a su baja viscosidad, baja osmolaridad y nula toxicidad para las células. La mayor pérdida de microsporas se produjo con gradientes de densidad del $50 \%$, mientras que los gradientes de 60 y $70 \%$, concentraron mayor densidad de microsporas (Tabla 4). Por tal razón se escogió el tratamiento con Percoll ${ }^{\circledR}$ al 70\% para la purificación de las microsporas de C. arabica.

Efecto del estrés térmico en el cultivo de microsporas de café. Los parámetros que modulan la iniciación de la androgénesis a partir del cultivo de microsporas son el estrés y factores genéticos, los cuales favorecen significativamente la producción de plantas haploides. El aumento de la intensidad del estrés aumenta la frecuencia de inducción de

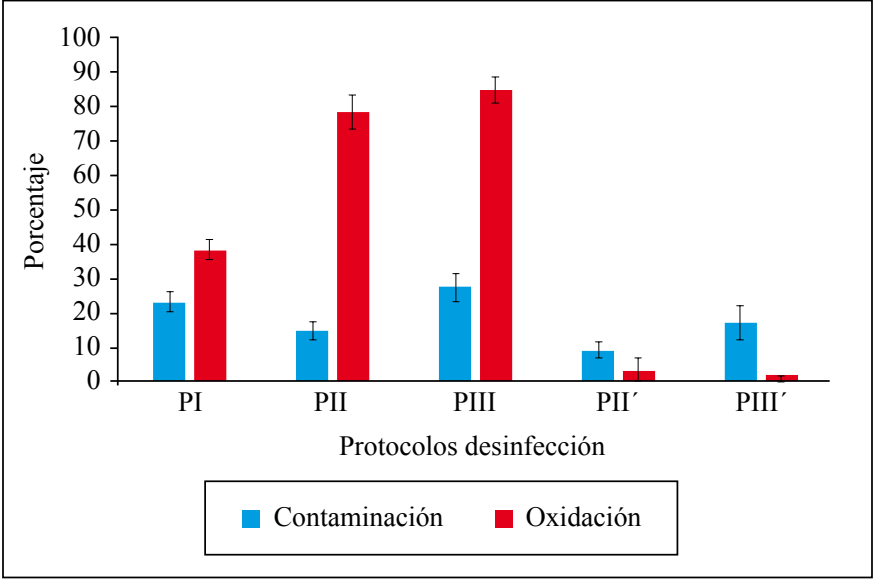

Figura 3. Evaluación de tratamientos para la desinfección superficial de botones florales de C. arabica. En el texto se describe detalladamente cada uno de los tratamientos aplicados a los botones florales. Los tratamientos PII' y PIII' son modificaciones de los tratamientos PII y PIII. 
la androgénesis, pero también puede afectar negativamente la viabilidad de las células e inducir re-arreglos en genomas nucleares o de cloroplastos que conducen a una disminución de la capacidad de regeneración y formación de plantas albinas (Zur et al., 2014; Rodríguez et al., 2012). El tratamiento en frío mejora la respuesta androgénica de las microsporas y se ha utilizado de forma rutinaria en cultivos de muchos cereales, como el maíz (Gaillard et al., 1991), trigo (Gustafson et al., 1995), cebada (Davies y Morton, 1998) y arroz (Cho y Zapata, 1988). El choque térmico combinado con la limitación de nutrientes (Touraev et al., 1996) o con el frío (Reddy et al., 1985) también son eficaces para reprogramar la ruta gametofítica. En el tratamiento a $4{ }^{\circ} \mathrm{C}$ donde se utilizaron botones florales de $C$. arabica sin desprendimiento de la rama el porcentaje de microsporas viables a los 7 días de incubación, justo antes de realizar el aislamiento mecánico de las microsporas, fue $57,5 \%$, y después de la purificación fue de $60,7 \%$. En el tratamiento a $4^{\circ} \mathrm{C}$ con botones desprendidos de la rama el porcentaje de células viables a los cinco días de incubación, antes de realizar el aislamiento mecánico de las microsporas fue de $70,8 \%$, y después de la purificación de $71,7 \%$. No hubo diferencias en la viabilidad de las células por efecto del protocolo de aislamiento mecánico ni se observaron diferencias significativas debido al desprendimiento de los botones florales (Figura 5 y 6).

Después de una semana de cultivo se observaron células en división en los dos tratamientos con estrés térmico (Figura 7a y b) y

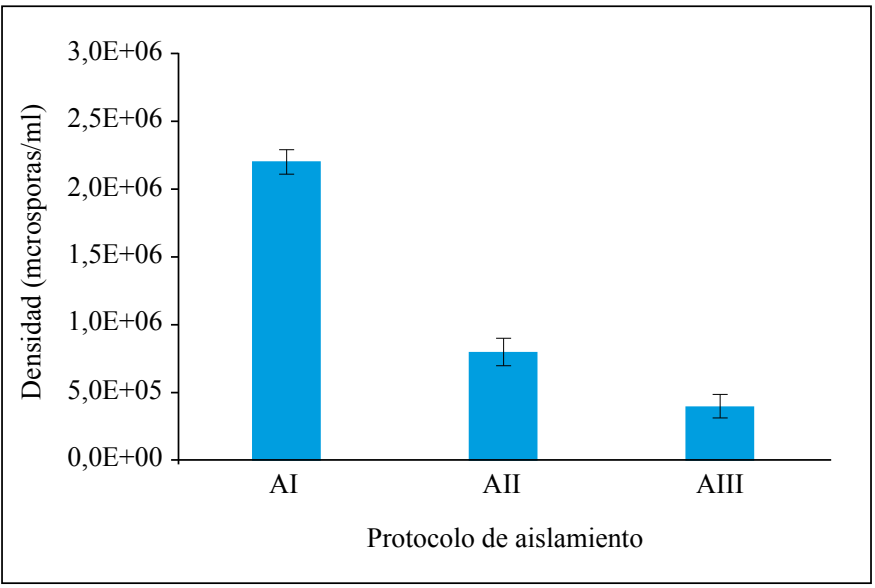

Figura 4. Evaluación de tratamientos para el aislamiento de microsporas de C. arabica.AI: aislamiento mecánico; AII: aislamiento por agitación; AIII: aislamiento con precultivo. Cada uno se evaluó en cuatro repeticiones y se determinó el promedio de la densidad de microsporas.

Tabla 4. Evaluación de los tratamientos para la purificación de microsporas de $C$. arabica en gradientes de Percoll $^{\circledR}$.

\begin{tabular}{|c|c|c|c|}
\hline $\begin{array}{c}\text { Tratamiento } \\
\text { Percoll } \\
\end{array}$ & $\begin{array}{c}\text { Densidad } \\
2(\text { microsporas } / \mathrm{mL}) \\
\end{array}$ & $\begin{array}{c}\text { Densidad } \\
(\mathrm{microsporas} / \mathrm{mL})\end{array}$ & $\begin{array}{c}\text { Pérdida } \\
\text { (microsporas } / \mathrm{mL})\end{array}$ \\
\hline $50 \%$ & $8,05 \times 10^{6}$ & $8,40 \times 10^{5}$ & $7,21 \times 10^{6}$ \\
\hline $60 \%$ & $9,55 \times 10^{5}$ & $4,90 \times 10^{5}$ & $4,65 \times 10^{5}$ \\
\hline $70 \%$ & $9,70 \times 10^{5}$ & $6,05 \times 10^{5}$ & $3,65 \times 10^{5}$ \\
\hline
\end{tabular}




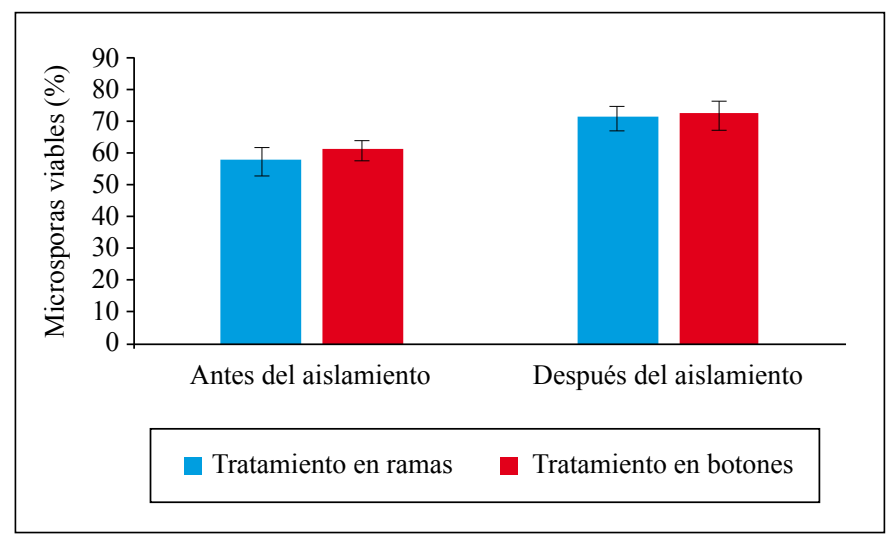

Figura 5. Evaluación de la viabilidad de microsporas de C. arabica obtenidas de botones florales desprendidos y no desprendidos de la rama y expuestos a $4^{\circ} \mathrm{C}$ en condiciones de oscuridad. Las barras son el porcentaje de microsporas fluorescentes antes y después de aplicar el tratamiento de aislamiento a las microsporas.

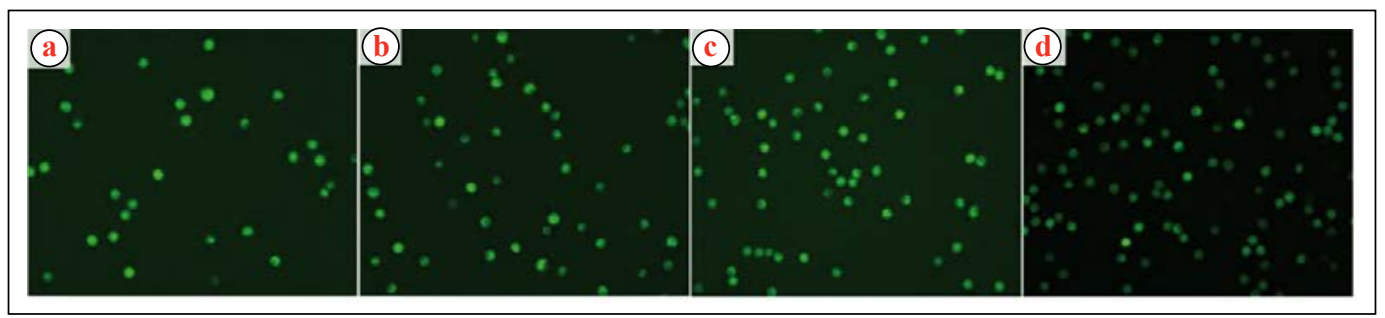

Figura 6. Viabilidad de microsporas mediante tinción con acetato de fluoresceína (10X). a. Microsporas de botones florales no desprendidos de la rama, siete días de incubación a $4^{\circ} \mathrm{C}$ en condiciones de oscuridad, antes de realizar el aislamiento; b. Microsporas de botones florales no desprendidos de la rama, siete días de incubación a $4^{\circ} \mathrm{C}$ en condiciones de oscuridad, después del aislamiento; c. Microsporas de botones florales desprendidos, cinco días de incubación a $4^{\circ} \mathrm{C}$ en condiciones de oscuridad, antes de realizar el aislamiento; $\mathbf{d}$. Microsporas de botones florales desprendidos, cinco días de incubación a $4^{\circ} \mathrm{C}$ en condiciones de oscuridad, después del aislamiento.

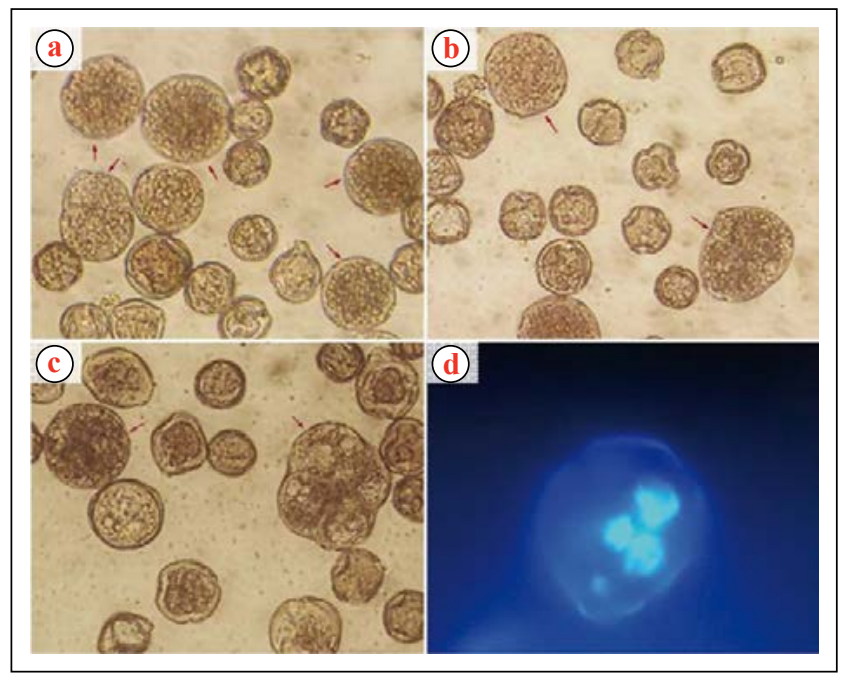

Figura 7. Androgénesis inducida por tratamiento a baja temperatura de microsporas de C. arabica. a. División celular de microsporas obtenidas de botones florales desprendidos; $\mathbf{b}$. División celular de microsporas obtenidas de botones florales no desprendidos de la rama; c. Colonias multicelulares observadas bajo microscopio invertido después de tres semanas de cultivo; d. Colonia multicelular teñida con el fluorocromo DAPI. 
al cabo de tres semanas se evidenciaron colonias multicelulares conformadas por cuatro a seis células (Figura 7c). En el tratamiento utilizando botones florales desprendidos de la rama se observó $4,7 \%$ de colonias celulares mientras que en el tratamiento con flores adheridas a las ramas el porcentaje de colonias fue de 1,4\%. En cuanto al control, no se observaron células en división. La división celular fue confirmada mediante tinción con DAPI (4',6-diamidino2-phenylindole), un fluorocromo específico de unión al ADN que permite observar bajo microscopía de fluorescencia los núcleos de las células (Figura 7d). Aunque se evidenció la formación de colonias multicelulares después de varias semanas de cultivo, estas no lograron sostener su crecimiento y no prosperaron en la formación de callos embriogénicos. Sin embargo, esta es la primera evidencia de formación de colonias celulares inducidas por estrés térmico en microsporas de $C$. arabica, lo que significaría que es un tratamiento promisorio para la optimización del proceso de androgénesis en café. En futuros experimentos es necesario evaluar por qué después de haber sido inducida la división celular se detuvo el crecimiento. Es posible que se requiera una composición hormonal específica del medio de cultivo, o determinada condición ambiental para mantener activa la división celular de estas colonias hasta la formación de embriones somáticos que produzcan plantas haploides.

\section{Duplicación cromosómica "in vivo" en} plantas haploides de $C$. arabica. Después de aplicar los tratamientos antimitóticos a las yemas ortotrópicas de plantas haploides cultivadas en el campo, se regeneraron nuevos tallos (chupones) con sus respectivas hojas. Estos fueron cortados de la planta madre y los esquejes se enraizaron en bolsas con suelo hasta la formación de plantas con tres a cuatro entrenudos. En el tratamiento con Colchicina (TRA1) se observó un 10\% de ramas con hojas duplicadas (RHD) y un $90 \%$ de ramas con hojas sin duplicar (RHSD), mientras que en el tratamiento con trifluralina (TRA2) solo se observaron ramas con hojas sin duplicar (Figura 8).

Las ramas de hojas duplicadas (RHD) tratadas con Colchicina (TRA1) tuvieron una menor relación longitud/ancho de la hoja (RELAH) 2,58 y densidad estomática (DE) 122,2 estomas $/ \mathrm{mm}^{2}$; en comparación con las ramas de hojas sin duplicar (RHSD) que presentaron una RELAH de 3,54 y una DE de 242,4 estomas $/ \mathrm{mm}^{2}$. Mientras

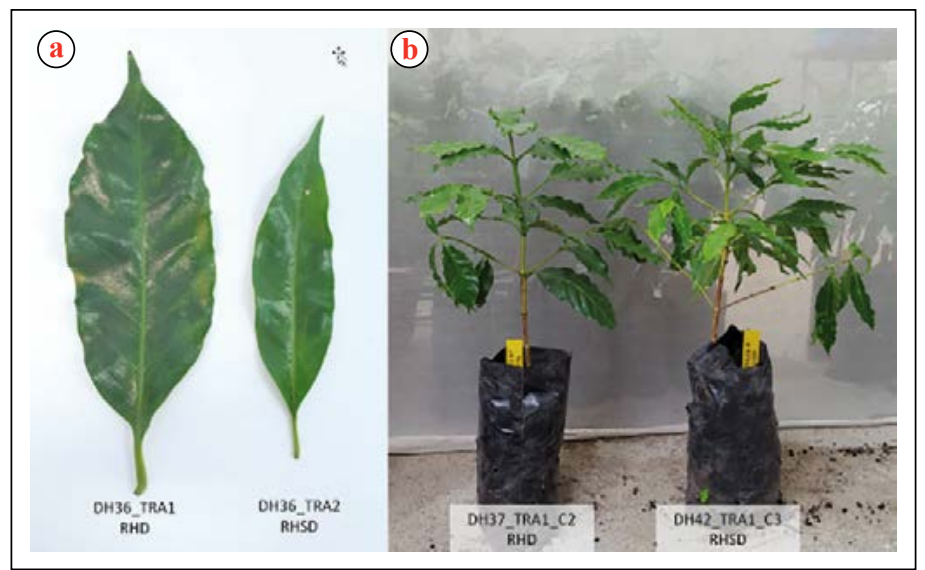

Figura 8. Características morfológicas de las ramas con hojas duplicadas (RHD) y las ramas con hojas sin duplicar (RHSD). a. Hojas tomadas de la planta DH36 tratada con Colchicina al $1 \%$ (TRA1) y Trifluralina al $0,01 \%$ (TRA2); b. Ramas enraizadas del tratamiento con Colchicina al $1 \%$ (TRA1), planta DH37 con hojas duplicadas (RHD) y planta DH42 con hojas sin duplicar (RHSD). 
que la longitud de las células guarda fue mayor en las RHD $(28,5 \mu \mathrm{m})$ con relación a las $\operatorname{RHSD}(20,2 \mu \mathrm{m})$, como se presenta en las Figuras 9 a las 12. Otra característica importante observada en las ramas con hojas sin duplicar fue la presencia de estomas fusionados, mencionada también por Herrera y Camayo (2008), que se debe al desequilibrio cromosómico que sufren las plantas haploides. Este análisis confirma que, las variables RELAH, DE y LONGE son discriminantes para el nivel de ploidía en plantas de café, debido que a menor relación longitud/ancho de la hoja, menor densidad estomática, mayor longitud de las células guarda, se produce duplicación cromosómica (Herrera y Camayo, 2008; Orozco y Cassalett, 1974; Sreenivasan et al., 1992; Mishra et al., 1991).

La evaluación del nivel de ploidía se relacionó con las variables antes evaluadas y se verificó que las ramas RHD contenían 44 cromosomas somáticos (Figura 13), lo cual indica una relación inversa con las variables RELAH y DE, y una relación directa con LONGE, confirmando que la ploidía en las plantas de café está asociada con la densidad estomática y la longitud de los estomas (Orozco y Cassalett, 1974).
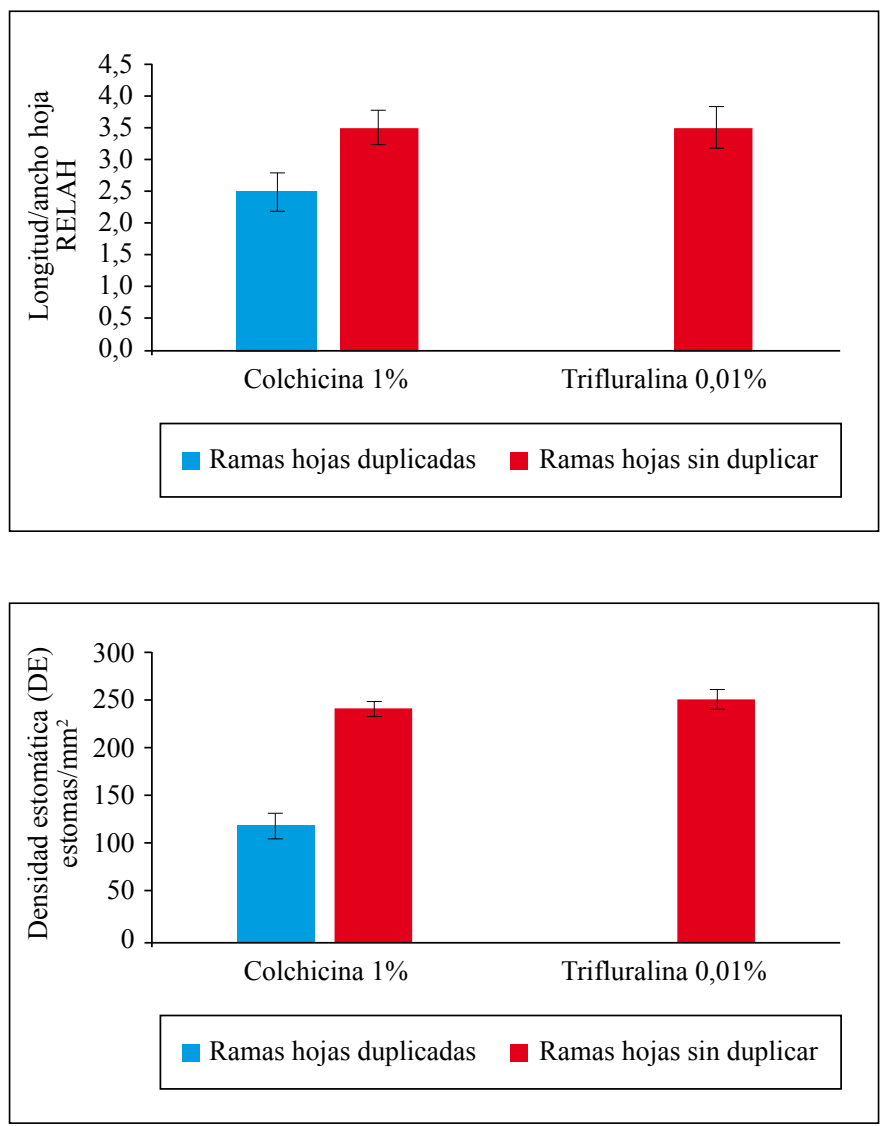

Figura 9. Evaluación de la relación longitud/ancho de las hojas en la duplicación in vivo. TRA1: tratamiento con colchinina $1 \%$; TRA2: tratamiento con trifluralina $0,01 \%$. Ramas con hojas duplicadas (RHD) y ramas con hojas sin duplicar (RHSD).

Figura 10. Evaluación de la densidad estomática de duplicación in vivo. TRA1: tratamiento con Colchicina $1 \%$; TRA2: tratamiento con trifluralina $0,01 \%$. Ramas con hojas duplicadas (RHD) y ramas con hojas sin duplicar (RHSD). 

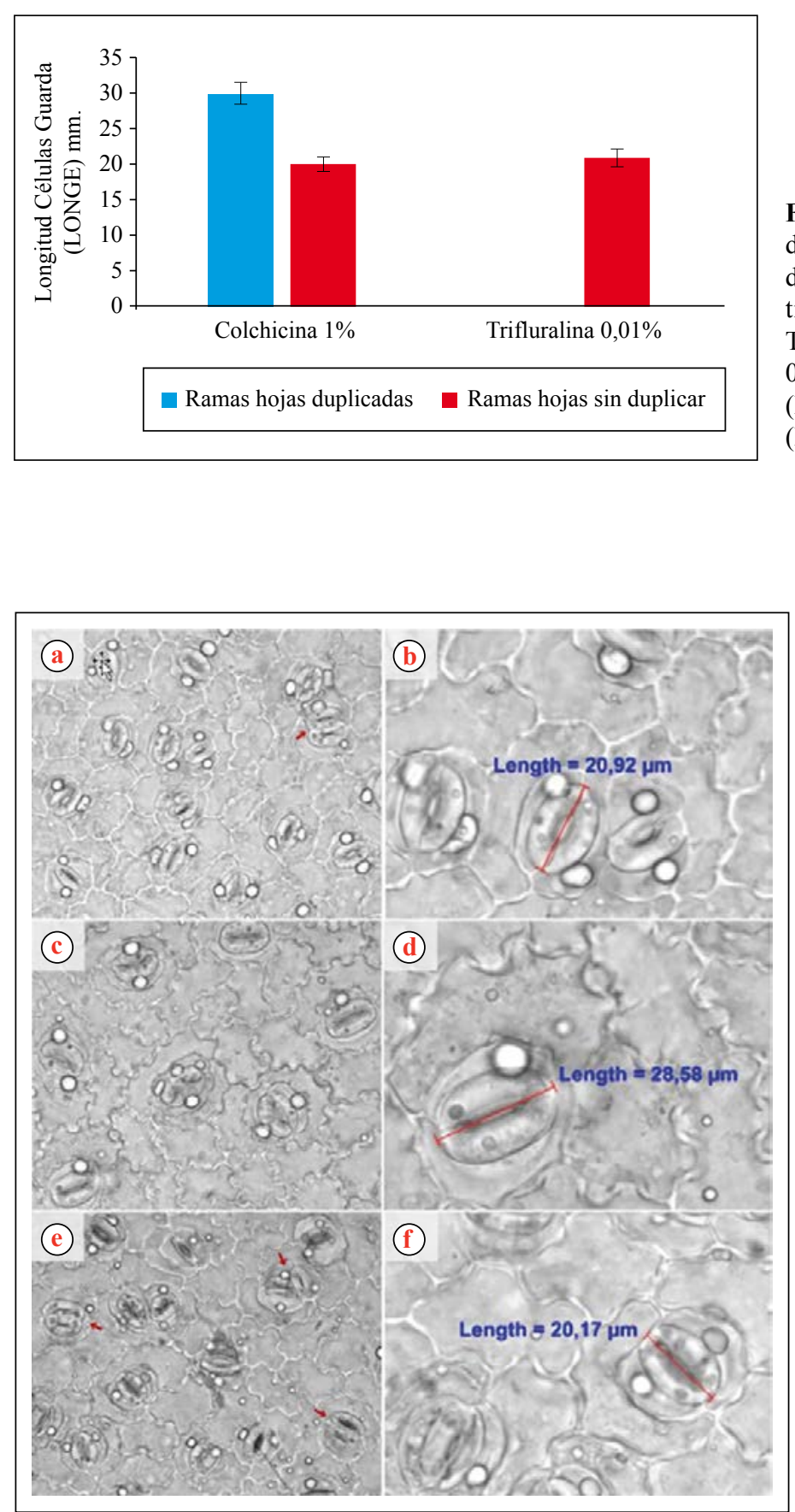

Figura 11. Evaluación de la longitud de las células guarda de estomas de duplicación in vivo. TRA1: tratamiento con Colchicina $1 \%$; TRA2: tratamiento con trifluralina $0,01 \%$. Ramas con hojas duplicadas (RHD) y ramas con hojas sin duplicar (RHSD).

Figura 12. Análisis citológico de las ramas con hojas duplicadas (RHD) y ramas con hojas sin duplicar (RHSD) con Colchicina al $1 \%$ (TRA1) y Trifluralina al $0,01 \%$ (TRA2). a. y b. Densidad estomática (DE) y longitud de las células guardas (LONGE) planta DH35, tratamiento con Colchicina (TRA1), estomas de mayor longitud y menor densidad estomática; c. y d. Densidad estomática (DE) y longitud de las células guardas (LONGE) planta DH42, tratamiento con Colchicina (TRA1), estomas de menor tamaño y fusionados (característica de las plantas $\mathrm{DH}$ ), mayor densidad estomática; e. y f. Densidad estomática (DE) y longitud de las células guardas (LONGE) planta DH43, tratamiento con Trifluralina (TRA2), estomas de menor tamaño y fusionados (característica de las plantas $\mathrm{DH}$ ), mayor densidad estomática. 


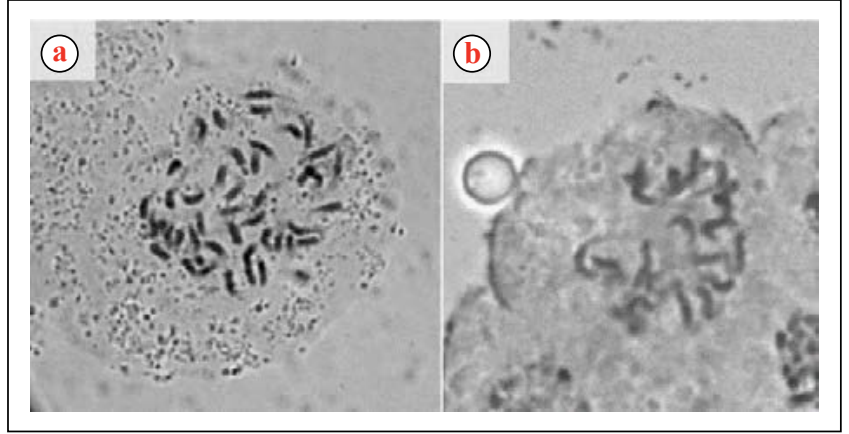

Figura 13. Microfotografía de los cromosomas de hojas desarrolladas después del tratamiento de duplicación in vivo (ensayo IV). a. ramas con hojas duplicadas (RHD) de la planta DH36; b. ramas con hojas sin duplicar (RHSD) de la planta DH36.

\section{AGRADECIMIENTOS}

El presente trabajo se realizó gracias al apoyo financiero de COLCIENCIAS por medio del contrato No. RC-0154-2012, correspondiente al proyecto: "Estudio de los factores limitantes para la obtención de plantas haploides en el mejoramiento del café en Colombia" (Código 2251-521-28565) y de la Federación Nacional de Cafeteros de Colombia.

\section{LITERATURA CITADA}

Berthou, F. (1975). Méthoded'obtention de polyploïdes dans le genre Coffea par traitements localisés de bourgeons à la colchicine. Café, Cacao Thé(Francia). 19(3), 197-202.

Caperta, A. D., Delgado, M., Ressurreição, F., Meister, A., Jones, R. N., Viegas, W., \& Houben, A. (2006). Colchicine-induced polyploidization depends on tubulin polymerization in c-metaphase cells. Protoplasma, 227(2), 147-153. https://doi.org/10.1007/s00709-005$0137-\mathrm{z}$

Cho, M. S., \& Zapata, F. J. (1988). Callus formation and plant regeneration in isolated pollen culture of rice (Oryza sativa L. cv. Taipei 309). Plant Science, 58(2), 239-244. https://doi.org/10.1016/0168-9452(88)90014-3

Davies, P. A., \& Morton, S. (1998). A comparison of barley isolated microspore and anther culture and the influence of cell culture density. Plant Cell Reports, 17(3), 206210. https://doi.org/10.1007/s002990050379
Gaillard, A., Vergne, P., \& Beckert, M. (1991). Optimization of maize microspore isolation and culture conditions for reliable plant regeneration. Plant Cell Reports, 10(2), 55-58. https://doi.org/10.1007/BF00236456

Gustafson, V. D., Baenziger, P. S., Wright, M. S., Stroup, W. W., \& Yen, Y.(1995). Isolated wheat microspore culture. Plant Cell, Tissue and Organ Culture, 42(2), 207-213. https://doi.org/10.1007/BF00034239

Herrera, J. C., Moreno, L. G., Acuña, J. R., De Peña, M., \& Osorio, D. (2002). Colchicine-induced microspore embryogenesis in coffee. Plant Cell, Tissue and Organ Culture, 71(1), 89-92. https://doi. org/10.1023/A:1016564816602

Herrera, J. C., \& Camayo, G. C. (2008). Caracterización morfológica y citológica de árboles de Coffea arabica L., regenerados por cultivo in vitro de polen aislado. Revista Cenicafé, 59(2), 143-154. http://hdl.handle. net/10778/131

Kasha, K., (2005). Chromosome doubling and recovery of doubled-haploid plants. En C. Palmer, W. Keller, \& K. Kasha (Eds). Haploids in Crop Improvement II. Biotechnology in agriculture and forestry (Vol. 56, pp. 123-152). Springer. https://doi.org/10.1007/3-54026889-8 7

Mishra, M., Prakash, N., \& Sreenivasan, M. (1991). Relationship of stomatal length and frequency to ploidy level in Coffea L. Journal of Coffee Research. 21(1), 32-41.

Neuenschwander, B., Dufour, M., Baumann, T.W.(1993, june 6-11). Haploid cell colony formation from mechanically isolated microspores of Coffea arabica [Conference session]. 15th International Scientific Colloquium on Coffee, Montpellier, France. https://www.asic-cafe.org/ 
conference/15th-international-scientific-colloquiumcoffee/haploid-cell-colony-formation

Noirot, M. (1978). Polyploïdisation de caféiers par la colchicine: Adaptation de la technique sur bourgeons axillaires aux conditions de Madagascar: Mise en évidende de chimères périclines stables. Café, Cacao Thé(Francia). 22(3), 187-194.

Orozco, F. J., \& Cassalett, C. (1974). Relación entre las características estomáticas y el número cromosómico de un híbrido interespecífico en café. Revista Cenicafé. 25(2), 33-50. http://hdl.handle.net/10778/1111

Raghuramulu, Y., \& Prakash, N. S. (1996). Haploidy in coffee. In Jain S.M., Sopory S.K., Veilleux R.E. (Eds.), Vitro haploid production in higher plants. Current Plant Science and Biotechnology in Agriculture (Vol. 25, pp. 349-363). Springer, Dordrecht. https://doi. org/10.1007/978-94-017-1858-5_18

Reddy, V.S., Leelavathi, S., \& Sen, S.K. (1985). Influence of genotype and culture medium on microspore callus induction and green plant regeneration in anthers of Oryza sativa. Physiologia Plantarum, 63, 309-314. https://doi.org/10.1111/j.1399-3054.1985.tb04271.x

Rodríguez-Serrano, M., Bárány, I., Prem, D., Coronado, M. J., Risueño, M. C., \& Testillano, P. S. (2012). NO, ROS, and cell death associated with caspase-like activity increase in stress-induced microspore embryogenesis of barley. Journal of Experimental Botany. 63(5), 20072024. https://doi.org/10.1093/jxb/err400
Sharp, W., Caldas, L., Crocomo, O., Monaco, L., \& Carvalho, A. (1973). Production of Coffea arabica callus of three ploidy levels and subsequent morphogenesis. Phyton, 31(2), 67-74.

Sreenivasan, M., Prakash, N., \& Mishra M. (1992). Evaluation of some indirect ploidy, indicators in Coffea L. Café, Cacao Thé(Francia). 36(3). 199-205.

Touraev, A., Indrianto, A., Wratschko, I., Vicente, O., \& Heberle-Bors, E. (1996) Efficient microspore embryogenesis in wheat (Triticum aestivum L.) induced by starvation at high temperature. Sexual Plant Reproduction, 9(4), 209-215. https://doi.org/10.1007/ BF02173100

Zoriniants, S., Tashpulatov, A.S., Heberle-Bors, E., \& Touraev, A. (2005). The role of stress in the induction of haploid microspore embryogenesis. En C. Palmer., W.A. Keller \& K.J. Kasha (Eds.) Haploids in Crop Improvement II. Biotechnology in Agriculture and Forestry (Vol. 56). Springer, Berlin, Heidelberg. https:// doi.org/10.1007/3-540-26889-8_3

Zur, I., Dubas, E., Krzewska, M., Janowiak, F., Hura K., Pociecha E., Bączek-Kwinta, R., \& Plazek, A. (2014). Antioxidant activity and ROS tolerance in triticale (x Triticosecale Wittm.) anthers affect the efficiency of microspore embryogenesis. Plant Cell, Tissue and Organ Culture. 119(1), 79-94. https://doi.org/10.1007/ s11240-014-0515-3 